\title{
O Cancioneiro Geral de Garcia de Resende e um problema de atribuição
}

Barbara Spaggiari

Universidade de Peruggia (Itália)

$\mathrm{N}$

o primeiro quartel do séc. XVI, saíram a lume duas antologias de poesia lírica que constituiram um marco na história das literaturas ibéricas. Em 1511, Hernando del Castillo publicou o seu Cancionero General, na esteira do qual, em 1516, veio ao público o Cancioneiro Geral organizado por Garcia de Resende. ${ }^{1}$ As duas obras, ligadas até no título, pretendem reunir uma ampla amostra da actividade poética das cortes, respectivamente, castelã e portuguesa, assim constituindo uma memória e, ao mesmo tempo, uma consagração daquela poesia palaciana que ia acabando o seu período de maior floração.

De facto, a recolha de Garcia de Resende ${ }^{2}$ abrange a poesia produzida em Portugal - não apenas em português, mas também em castelhano - de

${ }^{1}$ No rosto, surge apenas o título Cancio: | neiro, geral: | Cum prenilegio. Mais informações encontram-se no colofão: "Acabou-se de empremir o Cancioneiro Geeral, com previlegio do muito alto e muito poderoso Rei Dom Manuel nosso Senhor. [...] Foi ordenado e emendado por Garcia de Reesende, fidalgo da casa d'El-Rei nosso Senhor e escrivam da fazenda do Principe. Começouse em Almeirim e acabou-se na muito nobre e sempre leal cidade de Lixboa, per Hermam de Campos, alemam, bombardeiro d'El-Rei nosso Senhor e empremidor, aos XXVIII dias de Setembro da era de Nosso Senhor Jesu Cristo de mil e quinhentos e XVI anos».

${ }^{2}$ Pertencente à ilustre família dos Resende, Garcia nasceu em Évora, cerca de 1470 , e exerceu vários cargos ao serviço da corte. Ele próprio poeta 
meados do séc. XV até à data de publicação, sendo o texto mais antigo datável entre 1440 e $1447,{ }^{3}$ enquanto o mais novo remonta ao próprio 1516 , ano da ediçãao príncipe. ${ }^{4}$

palaciano e memorialista, participou no Cancioneiro Geral com composições "de folgar», mais umas Trovas à morte de Inês de Castro, que constituem a primeira consagração literária desta trágica personagem. Faleceu em 1536. ${ }^{3}$ É esta a datação tradicional, aceita por Margarida Vieira Mendes (1993), enquanto Aida Dias, vol. V (1998), p. 76, indica como termo ante quem o 20 de Maio de 1449, data do desastre de Alfarrobeira, com base no texto II, n. ${ }^{\circ} 256$.

${ }^{4}$ Como vimos, a impressão ocorreu antes em Almeirim, e depois em Lisboa, na oficina de Hermão de Campos (Kempis ou von Kempen), impressor de Dom Manuel I. Existem, hoje em dia, uma dezena de exemplares da 'princeps', que divergem nomeadamente nos primeiros sessenta fólios e, ainda, no colofónio. A análise de Helena Marques Dias e Ivo Castro, baseada nos princípios da 'Bibliography' anglo-saxônica, permitiu avançar a hipótese seguinte: «a edição príncipe do Cancioneiro Geral existe em dois estados, A e B, que fundamentalmente se distinguem quanto à sua extensão, aos materiais e ao estilo de composição tipográfica, bem como quanto à ortografia e à lição do texto. Os estados foram compostos separadamente e por indivíduos diferentes, provavelmente impressos em momentos afastados, mas as folhas de ambos foram misturadas antes de alçados e encadernados os volumes [...]». A tipologia assinalada corresponde a um dos acidentes da produção tipográfica descrito por Fredson Bowers: "o refazer parcial da composição de um livro, a meio do processo de produção, com o objectivo de aumentar a tiragem ou de substituir folhas impressas destruídas» (v. Helena Marques Dias e Ivo Castro, "A edição de 1516 do 'Cancioneiro Geral' de Garcia de Resende», Revista da Faculdade de Letras, IV,1, 1976-1977, p.119). Esta conclusão é contestada por Aida Dias com base em algumas variantes triplas, que contradiriam a existência de «variantes sempre binárias», afirmada por Marques e Castro (Dias, vol. V, 1998, p.91-92). Dias chega, por sua conta, à conclusão de que os exemplares «acusam a mão de dois compositores diferentes», mas os acidentes evidenciados dependem da «deslocação da tipografia de Hermão de Campos de Almeirim para Lisboa» (ibid., p.93). 
O volume in-fólio, de grande qualidade e apuro, contém 232 fólios com duas ou três colunas por página, executadas em caracteres góticos. ${ }^{5}$ Foi dedicado pelo organizador ao futuro D. João III. No breve Prólogo, Garcia de Resende declara a intenção de trazer à memória « muitas cousas de folgar e gentilezas [que] sam perdidas, sem haver delas noticia». Sendo poesia feita por cortesãos e para cortesãos, a tarefa de reunir os originais foi provavelmente menos árdua do que os ordenar dentro da colectânea.

A questão do arranjo, ou da ordenação dos poemas dentro dos cancioneiros, sejam eles individuais ou colectivos, constitui, como é sabido, um dos aspectos mais focados nas últimas décadas pelos investigadores, a partir do Canzoniere de Petrarca nas suas 'formas' sucessivas, até a estrutura das várias colectâneas dos séculos XV e XVI. ${ }^{6}$

5 Sobre as características comuns aos cancioneiros peninsulares, v. Jorge A. Osório, "Do cancioneiro 'ordenado e emendado' por Garcia de Resende», in Revista da Faculdade de Letras. Linguas e Literaturas, Universidade do Porto, II Série, vol. XXII, Porto, 2005, p.291-335, nas p. 297-298: «Estes cancioneiros impressos caracterizam-se por diversos aspectos : por usarem letra do tipo gótico, que até bastante tarde fez parte da "imagem" da página impressa com textos em língua vulgar [...]; por trazerem uma folha de rosto que se resume à designação titular, deixando-se as demais informações tipográficas (local de impressão, data, nome do tipógrafo, etc.) para o colofão final, segundo a tradição herdada dos códices manuscritos do século anterior ; por, numa estratégia de economia de papel, disporem o texto em duas ou três colunas, conforme a extensão dos versos; por usarem uma linguagem informativa em enunciados de função didascálica, ou seja paratextos que identificam autores e obras, além de comportarem dados extratextuais ou circunstâncias de referenciação histórica».

${ }^{6}$ Além do estudo fundamental de Jorge A. Osório, acima citado, que pela primeira vez analisa detidamente deste ponto de vista o Cancioneiro Geral de Resende, remete-se para Rita Marnoto, O Petrarquismo português do Renascimento e do Maneirismo, Coimbra, Por ordem da Universidade, 1997; e, da mesma autora, "A forma cancioneiro e a edição dos Poemas Lusitanos de 1598: Petrarquismo forte e Petrarquismo débil», in Estudos para M. Idalina 
No caso do Cancioneiro Geral de Garcia de Resende, os critérios de disposição não são sistemáticos nem unívocos, o que dificulta até a identificação do número exacto quer dos autores antologizados, quer dos poemas coligidos. Teófilo Braga apontou 350 nomes, Inocêncio 286; com efeito, os autores de peças individuais são cerca de cem, mas a eles é preciso acrescentar perto de duzentos 'intervenientes', sendo alguns deles meramente fictícios. Devido à sua natureza, torna-se, aliás, difícil estabelecer, por vezes, qual é o começo e qual o fim de certas composiçôes, e isso nomeadamente no caso dos debates, das ajudas, das perguntas e respostas, ou das trovas de correspondência. ${ }^{7}$

Como se pode apreender da Tavoada que antecede o Prólogo, ${ }^{8}$ no próprio começo do volume, os textos poéticos foram divididos por Garcia de Resende em três secçôes: a primeira, sem título, que vai até à f. 142 (cxlii); a segunda, chamada DE LOUVOR, que ocupa as ff. 142-154 (cxlii-cliiii); a terceira, das COUSAS DE FOLGAR, que começa na mesma f.154. ${ }^{9}$

Resina Rodrigues, M. Lucilia Pires, M. Vitalina Leal de Matos, org. de I. Almeida, M. I. Rochera, T. Amado, Lisboa, Departamento de Literaturas Românicas, 2007, p. 807-819, com a bibliografia relativa.

${ }^{7} \mathrm{Na}$ sua edição, vol. V, p. 76, Aida Dias afirma tratar-se de «880 composiçōes de 345 autores (não contando os anónimos nem as autorias fictícias)», mas nunca encara a questão fundamental dos critérios com que foi 'ordenado' o Cancioneiro Geral de Garcia de Resende.

${ }^{8}$ Título por extenso: TAVOADA DE TODALAS COUSAS QUE ESTAM NESTE LIVRO ASSI EM ORDEM COMO NELE VAM E NAS COUSAS DE FOLGAR ACHARAM UM SINAL COMO ESTE ?. O sinal, na realidade, nem sempre está colocado no lugar onde seria pertinente.

${ }^{9}$ Com respeito a esta divisão preliminar, as coisas procedem de forma algo diferente, ainda que substancialmente não contradictória. As poesias «de folgar» chegam até a f. 182 ; daí por diante, encontra-se mais um grupo de composiçōes que não cabe em alguma das secçoes anteriores, partilhando certas características com o grupo inicial do volume. Com efeito, o último sector abrange, a par do primeiro, cancioneiros privativos, isto é, conjuntos homogéneos e 
Conforme a Tavoada, ${ }^{10}$ tratar-se-ia de um cancioneiro colectivo estruturado por géneros e, dentro dos géneros, por autores. Apesar disso, no interior do volume não constam partes ou secções ou conjuntos que sejam assinalados de forma explícita, ou então, que estejam formalmente individualizados. Neste aspecto, o Cancioneiro Geral diferencia-se das semelhantes recolhas de área castelã, que retomam a prática, já medieval, de identificar as várias secções, além de assinalar pela epígrafe o nome do autor e, por vezes, a ocasião em que o poema foi composto.

Precisamente as epígrafes que encabeçam as composições do Cancioneiro Geral, destinadas em princípio a assegurar a correcta atribuição dos textos, é que podem alimentar as dúvidas no momento de individuar a identidade autoral da peça a seguir. Isto acontece nomeadamente nas epígrafes do tipo "Cantiga sua», «Outra sua», «Outras suas» (trovas ou

significativos de autores susceptíveis de figurar noutros lugares do Cancioneiro Geral com contribuições dispersas em obras colectivas. A diferença mais patente entre o primeiro e o último sector de arrumação dos poemas reside na datação: no começo, aparecem autores que pertencem a um período mais antigo, tais como o Condestável D. Pedro, enquanto a secção final apresenta poetas de uma geração mais nova, como Henrique da Mota ou o próprio Garcia de Resende.

${ }^{10} \mathrm{O}$ índice inicial, a par da(s) dedicatória(s), do(s) prólogo(s) com carácter justificativo ou doutrinário, e das peças laudatórias, constitui, em volumes desta época, um dos elementos principais do paratexto. Mas, à diferência do que acontece no Cancionero General de Castillo, "Resende não instituiu qualquer tipo de divisóes ou apartados internos, fossem definidos por critérios geracionais ou de género poético; por outro lado, passou à margem da reflexão doutrinária sobre o que se devia entender por poesia [...]. Mais: Resende deixa de lado um ponto que os castelhanos puseram em destaque: o enaltecimento da própria língua. [...] Como é sabido, não foi esse o caminho seguido por Garcia de Resende no seu 'Prólogo' dirigido ao príncipe herdeiro do trono D. João. O argumento fundamental aí utilizado [...] reside na ideia de que aos feitos de conquista de um tão forte monarca imperial tinham de corresponder os feitos poéticos da sua corte». (Osório, p. 298-299) 
coplas), em que a atribuição, sendo implícita, surge apenas da colocação do texto dentro do 'continuum' do Cancioneiro Geral.

Na secção inicial do Cancioneiro, que é visivelmente a mais extensa, logo depois da tenção poética sobre o Cuidar e Sospirar que ocupa as ff. I-XV, ${ }^{11}$ encontra-se uma sucessão de cancioneiros individuais, ${ }^{12}$ que praticamente estão ausentes das composiçôes colectivas. Os cancioneiros individuais são «conjuntos normalmente de extensão variável, mas não muito significativa, de uma diversidade de autores, às vezes com sequências que parecem fazer parte do que se diria um cancioneiro de família, como pode ter sido o caso dos conjuntos de João Rodrigues de Castelo Branco, logo seguido do de Rui Gonçalves de Castelo Branco» (Osório, p. 303).

Com efeito, da f. CVIr à f. CIXr surgem algumas composições poéticas atribuídas a dois representantes da família dos de Castelo Branco, que tinha sido recentemente confirmada no condado. ${ }^{13}$ Conforme nos dizem as

11 Trata-se, como é sabido, de um poema colectivo em forma de debate, organizado segundo um esquema judicial, em que intervêm vários autores da corte joanina. Foi realizado nos anos 1483-1484 e conta 3172 versos de arte real ou redondilha maior. Do ponto de vista do género, é uma tenção na tradição da tenson provençal, que tem como argumento a disputa acerca do amador que melhor ama: «se o que muito cuida ou o que muito suspira, isto é, se o que cala os sentimentos do amor ou aquele que os exterioriza». A disputa organiza-se, portanto, através de uma série de estrofes justapostas (as ajudas), de vez em quando finalizadas por um dito ou uma sentença. 12 Isto é, "conjuntos poéticos que parecem ter origem em "cancioneiros" individuais, provavelmente conservados entre os bens culturais dos autores ou das suas famílias, possuidores de uma unidade razoável e em que se destacam, tanto pela posição inicial, como mesmo por alguma extensaõ, os de alguns nomes acima referidos» (Osório, p. 303-304).

${ }^{13}$ A D. Martinho de Castel Branco «por carta de Dezembro de 1497, foramlhe confirmados o senhorio de Vila Nova de Portimão, com a jurisdição, os direitos reais desta vila e de Santarém e o reguengo de Chantas, tudo em sucessão a seu pai. Em 1504, D. Manuel fez D. Martinho de Castel Branco Conde de Vila Nova de Portimão", mas a data de publicação do condado é 12 de Fevereiro de 1514 (Dias, t. VI, p. 163). 
epígrafes, trata-se de Joam Rodriguez de Castel Branco, cujos poemas ocupam os n. ${ }^{\text {os }}$ II 393 a II 396 (ed. Dias), a quem logo sucede Rui Gonçalvez de Castel Branco com um conjunto de quinze composições (II 397 a II 412).

As notícias históricas concernentes aos dois personagens são escassas, além do que se pode tirar directamente de seus poemas. Graças às duas cartas em versos, ou epístolas métricas, endereçadas por João Rodrigues de Castelo Branco respectivamente a António Pacheco, vereador da moeda de Lisboa, ${ }^{14}$ e a Antam da Fonseca, comendador de Rosmaninhal, ${ }^{15}$ conhecemos a função de "contador da Guarda» exercida pelo autor, numa data que não podemos precisar, mas que se coloca entre os fins do século XV e o princípio do século XVI.

O seu contemporâneo, além de consanguíneo, Rui Gonçalves de Castelo Branco deixou mais traços da sua passagem na corte de D. Afonso V. Cavaleiro-fidalgo, assumiu vários cargos como tesoureiro e vedor da Moeda, contador da Comarca e corregedor da Guarda (o seu nome aparece, nomeadamente, em documentos de 1462 e de 1478).

A vintena de composições que vêm sob o nome de João Rodrigues e de Rui Gonçalves no Cancioneiro Geral de Garcia Resende, apesar da limitada extensão do conjunto, apresentam profundas divergências do ponto de vista quer temático, quer formal.

O conjunto de João Rodrigues de Castelo Branco abrange quatro peças de natureza variada: primeiro, encontram-se as duas epístolas rimadas a que já acima aludimos. Trata-se de poemas longos, ${ }^{16}$ algo extravagantes com

${ }_{14}$ Cf. II, n. 393 Mafoma, primo, senhor (vol. II, p. 312-316); epígrafe: De Joam Rodriguez de Castel Branco, contador da Guarda, a Antonio Pacheco, veador da Moeda de Lixboa, em reposta d'ua carta que lhe mandou, em que mortejava dele.

${ }^{15}$ Cf. II. n. 394 Porque sempre em vos servir (vol. II, p. 316-320); epígrafe: Trovas que mandou Joham Rodriguez de Castel branco a Antam da Fonseca, comendador de Rosmaninhal, a Alcacer-Seguer, em reposta doutras.

16 São, respectivamente, 136 e 144 versos heptassílabos organizados em oitavas (redondilha maior) com esquema rímico variável. 
respeito aos géneros frequentados no Cancioneiro Geral, por tratar-se de cartas em verso enviadas, respectivamente, a um primo residente em Lisboa, e a um combatente na África. Ambas partilham o mesmo tema da vida na aldeia, escolhida depois de ter longamente experimentado as intrigas e as malquerenças da corte. Com efeito, na esteira da aurea mediocritas horaciana, vários poetas da época ${ }^{17}$ procuram o isolamento da vida provinciana, longe da cidade e dos transtornos da vida cortesã. Esta oposição entre cidade e campo, entre corte e aldeia, leva João Rodrigues de Castelo Branco a exaltar a sua nova condição de 'beirão' ${ }^{18}$ em contraste tanto com o remanso do paço, como com os riscos ocorridos em longínquas empresas bélicas.

Como terceira composição, a II 395, surge a glosa a um vilancete em língua castelhana. O vilancete, normalmente anónimo, precede a Grosa de Joam Rodriguez de Castel Branco, que respeita as regras deste género poético, muito em voga nos séculos XV-XVI. Cada verso do Texto vem repetido e encabeça a Glosa correspondente; sendo o texto do vilancete de 10 versos heptassílabos, no caso em apreço a glosa resulta composta de 10 estrofes cada uma de 10 versos, igualmente heptassílabos, com esquema rímico variável. ${ }^{19}$ Aí também deparamos com um poema bem extenso, de tema

${ }^{17}$ No próprio Cancioneiro Geral, vejam-se por exemplo Nuno Pereira (I 88) e Diogo de Melo (IV 627). O modelo desta renúncia à vida mundana virá a ser, evidentemente, Francisco Sá de Miranda no seu recanto da Tapada.

${ }^{18}$ Como lembra Aida Dias, t.V, p.361 «a Beira é [...], nos séculos XV e XVI, uma região indiciada como símbolo de rusticidade». O próprio testemunho de João Rodrigues de Castelo Branco na carta a António Pacheco não deixa dúvidas a este respeito : "Saberês que sam tornado / des que vivo nesta Beira, / hetego, magro, coitado / e rebusto em grã maneira. / Tam disforme, tam beiram / que com quanto me querês. / ja vos nam contentarês / ser meu primo com irmão» II, 393, vv. 17-24).

${ }^{19}$ Sobre a tipologia da glosa v. B.Spaggiari, «Il genere della glosa nelle letterature iberiche del Cinquecento", in Atti del XXXI Convegno Interuniversitario "La citazione» (Bressanone-Brixen, 11-13 luglio 2003), Padova, 2009, p. 275-283. 
amoroso e de meio pastoral, que se afasta da tipologia das cantigas predominante no Cancioneiro Geral.

Em quarto e último lugar, o conjunto apresenta o poema a seguir:

$\begin{array}{cl}\text { II, n. } 396 & \text { CANTIGA SUA, PARTINDO-SE. } \\ & \text { Senhora, partem tam tristes } \\ \text { meus olhos por vós, meu bem, } & \text { que nunca tam tristes vistes } \\ & \text { outros nenhus por ninguem. } \\ & \text { Tam tristes, tam saudosos, } \\ & \text { tam doentes da partida, } \\ & \text { tam cansados, tam chorosos, } \\ & \text { da morte mais desejosos } \\ & \text { cem mil vezes que da vida. } \\ & \text { Partem tam tristes os tristes, } \\ & \text { tam fora d'esperar bem } \\ & \text { que nunca tam tristes vistes } \\ & \text { outros nenhus por ninguem. }\end{array}$

Como bem releva Andrée Crabbé Rocha, «o encanto desse poemeto resulta duma espontânea (ou sábia) combinação de efeitos literários, em que a isotopia da tristeza é realçada por uma acumulação de adjectivos do mesmo registo [...], pelo emprego sistemático do superlativo, e pela hiperbolização do clássico desejo de acabar de vez com o sofrimento, sem falar no ritmo e na musicalidade do trecho que, assim, facilmente consentiu a interpretação cantada que teve na voz de Amália Rodrigues, e permanece na nossa memória como prova de que nem tudo, no Cancioneiro, desmerece o nome de poesia» (Dicionário de Literatura Medieval, p.337-338).

De facto, apesar desta espontaneidade aparente a cantiga "partindose» desenvolve motivos de ascendência trovadoresca: ao tema dos olhos associa-se o da partida, num jogo subtil e complexo de iterações e de variações, baseado num núcleo compacto de adjectivos (tristes, saudosos, doentes, cansados, chorosos), com que o autor justifica o desejo de acabar com o sofrimento amoroso. 
Se agora examinarmos os três poemas que a precedem no Cancioneiro Geral (II 393, II 394 e II 395), todos explicitamente atribuídos pelas epígrafes a João Rodrigues de Castelo Branco, força é de constatar o abismo que os separa desta cantiga fascinante pelo género, pela versificação, pela temática e pelo estilo. Põe-se então a questão da autoria, que merece ser esclarecida, pois a epígrafe "Cantiga sua, partindo-se» deixa intacta a dúvida acerca do verdadeiro autor.

A contiguidade do conjunto atribuído a Rui Gonçalves de Castelo Branco sugere a hipótese de que a cantiga II 396, última peça do grupo anterior, pertença na realidade ao cancioneiro individual deste segundo representante da família Castelo Branco. A análise do 'corpus' de quinze composiçôes que lhe são conferidas no Cancioneiro Geral de Resende permitir-nos-á averiguar esta hipótese.

A peça II 397, encabeçada pela epígrafe «De Rui Gonçalvez de Castel Branco", é constituida por trovas sobre o desconcerto do mundo; logo a seguir, aparecem cinco cantigas, II 398 a II 402, duas das quais desenvolvem o tema da partida:

$$
\begin{array}{ll}
\text { II, n. } 399 & \text { OutRa de RuI GonçALVEZ. } \\
& \text { Que de meus olhos partais } \\
& \text { em qualquer parte qu'esteis, } \\
\text { em meu coraçam ficais } & \text { e nele vos converteis. } \\
& \text { Est'ee o vosso lugar } \\
& \text { em que mais certa vos vejo, } \\
\text { porque nam quer meu desejo } & \text { que vos di possais mudar. } \\
& \text { E por isso que partais, } \\
& \text { em qualquer parte que esteis, } \\
& \text { em meu coraçam ficais. } \\
\text { pois nele vos converteis. }
\end{array}
$$




\section{II, n. ${ }^{\circ} 402$ OUTRA SUA EM UA PARTIDA. \\ Lembra-me qu'hei-de partir, nam no posso afirmar, com'hei-de poder sofrir o que nam ouso cuidar? \\ Estaa em tal deferença comigo meu coraçam que me defenda a rezam contr'ela me dá licença. Desespero de partir 10 com vida deste lugar, porque soo de o cuidar começa a alma de sair. ${ }^{20}$}

No primeiro texto em apreço, aos motivos dos olhos e da partida acrescenta-se o tema do coração em que se fixa a imagem da mulher amada, até nele se converter. Na segunda cantiga, a partida coincide com a morte, pois só de pensar em afastar-se da mulher amada provoca a saída da alma e, com ela, da vida. Apesar de serem alguns dos topoi mais frequentados da literatura trovadoresca, os antigos lugares-comuns recuperam nova vitalidade nos versos de Rui Gonçalves de Castelo Branco, graças também ao ritmo encantador da redondilha.

Não é preciso sublinhar ulteriormente as afinidades tão manifestas que existem entre as três "cantigas da partida» que acabamos de analisar, II 396, II 399 e II 402. Semelhantes na temática de inspiração trovadoresca, apresentam a mesma tipologia métrica, a saber, uma estrofe inicial de quatro versos $a b b a$, seguida por outra de seis, com ordem variável das rimas (esquema de redondilha maior). O ritmo cativante dos versos deriva do habilidoso manejo de acentos e rimas, num exercício poético onde a singeleza é só aparente. A mesma marca estílistica sendo, portanto, reconhecível nas três

${ }^{20}$ Neste verso, a lição começa alma de sair aceite por Dias é hipométrica. Trata-se de haplografia. 
peças, força é concluir que elas pertencem verdadeiramente ao mesmo autor, Rui Gonçalves de Castelo Branco.

No que diz respeito à etiologia do erro de atribuição, várias explicações podem aventar-se, todas, porém, conexas com a actividade de ajuntamento dos textos poéticos que confluiram no Cancioneiro Geral. ${ }^{21} \mathrm{O}$ próprio compilador do Cancioneiro, Garcia de Resende, alude aos meios com que conseguiu recolher os poemas nas passagens em que se refere «a pedidos seus ou a remessas por parte de alguns trovadores» (Osório, p. 310). De facto, a produção poética da corte portuguesa nos finais do século XV e inícios do seguinte "participava de uma circulação feita de envios e recepçôes, umas vezes em jeito de oferta, outras certamente visando a constituição de cancioneiros, alguns ditos 'de mão'».

Dispersa e fragmentária por sua própria natureza, a poesia palaciana surgia ligada a circustâncias ocasionais no meio cortesão, e vivia da troca, do intercâmbio poético, num jogo de envios e respostas, perguntas e debates. O esforço de Garcia de Resende em coleccionar o mais completo acervo poético possível da corte régia deparava quer com essas dificuldades objectivas, devidas à maneira peculiar de divulgação da poesia palaciana,

${ }^{21}$ Por exemplo, o deslocamento mecânico de uma folha manuscrita, acontecida antes ou depois de ser o conjunto recebido pelo organizador do cancioneiro; ou então, o envio de poemas provindos do acervo de uma mesma família (como poderia ser o caso dos Castelo Branco, mas também dos Meneses, dos Pereira, dos Silveira, dos Sá, cujas composiçôes estão igualmente reagrupadas na primeira secção do Cancioneiro Geral). É verosímil supor que o material não foi completamente recolhido antes de ir para a tipografia e que «em alguns casos poderá ter havido alguma desatenção no respeitante aos textos, hipoteticamente em consequência de eles serem oferecidos em folhas ou cadernos autorais organizados com menos cuidado, escapando também a uma revisão final» (Osório, p. 333). Outro aspecto que pode ter influenciado negativamente a correcta arrumação dos cancioneiros individuais, concerne às circunstâncias exteriores da impressão, que decorreu em duas tipografias diferentes, como foi acima indicado. 
quer com «a resistência ou perguiça de alguns autores em fornecerem as suas poesias» (Osório, p.311).

Entre as alusões à actividade do compilador, que se encontram ao longo do Cancioneiro Geral, destaca-se precisamente a trova de envio com que o próprio Rui Gonçalves de Castelo Branco encerra o seu 'cancioneiro individual':

\section{II, n. $^{\circ} 412$ TROVA SUA QUe MANDOU a Garcia DE RESENDE COM ESTAS TROVAS.}

Porque nam haja memoria

de tam mal aventurado, pond'isto entitulado em quem disso levar groria. Que bem mal pareceria, em cancioneiro posto, homem sem vida nem gosto vir-lhe tal à fantesia.

Tal é a preocupação do fidalgo, que ele põe «entitulado», a saber, as rubricas que encimam as composições, no intuito de evitar que a «homem sem vida nem gosto" possa atribuir-se não apenas a autoria dos textos, mas sobretudo os sofrimentos e a infelicidade amorosa que neles se exprime. ${ }^{22}$

É, com isso, bem singular o facto de precisamente a mais famosa das cantigas acima analisadas, a qual foi composta, segundo a nossa hipótese, por Rui Gonçalves de Castelo Branco, continuar a ser atribuída a outro fidalgo da mesma família, João Rodrigues, o qual, nos seus versos autênticos, ignora de forma programática o registo convencional do serviço das damas e a temática amorosa de ascendência cortês. Como vimos, a causa

22 Essa reivindicação de uma primazia cultural e social condiz com o cuidado «de os seus versos irem ser incluídos num cancioneiro impresso», porque «o acto de pôr em livro acarretava uma nova condição para um conjunto poético» que, até então, tinha circulado exclusivamente de forma manuscrita na esfera restrita da aristocracia (as citações entre aspas provêm de Osório, p. 312). 
desta atribuição errônea decorre provavelmente da própria maneira de instituir a sequencialidade no interior de conjuntos individuais através daquelas fórmulas cantiga sua, ou outra(s) sua(s), onde o pronome possessivo sua em aposição ("possessivo posposto»), ou o demonstrativo outro («remissão anafórica») parecem traduzir «essencialmente a ideia de adição progressiva» (Osório, p. 329), sem cuidar no elemento referencial que, nas epígrafes deste formato, demora necessariamente implícito.

\section{Bibliografia Activa}

Cancioneiro Geral de Garcia de Resende. Lisboa, por Hermão de Campos, 1516.

Edição fac-símile da 'princeps': New York, Kraus, 1967.

\section{Edições integrais}

por Gonçalves Guimarães, Coimbra, Imprensa da Universidade, 1910-1917, 5 vols;

por Andrée Crabbé Rocha, Lisboa, Editorial Verbo, 1962 (Nova ed., Lisboa, Centro do Livro Brasileiro, 1973);

por Aida F. Dias e A. J. da Costa Pimpão, Coimbra, Centro de Estudos Românicos, 1973, 2 vols;

por Aida Fernandes Dias, Lisboa, INCM, 1990-2003, 6 vols. (aqui utilizada como ed. de referência).

\section{Bibliografia Passiva}

Andrée Crabbé Rocha, Aspectos do Cancioneiro Geral, Coimbra, Coimbra Editora, 1949.

Ead., Esboços dramáticos no Cancioneiro Geral, Coimbra, Coimbra Editora, 1951. 
Ead., Garcia de Resende e o Cancioneiro Geral, Lisboa, Instituto de Cultura Portuguesa, 1979 («Biblioteca Breve»).

Ivo Castro e Helena Marques Dias, "A edição de 1615 do Cancioneiro Geral», in Revista da Faculdade de Letras de Lisboa, n. 1 (1976-1977). p. 93-125.

Aida Fernanda Dias, O Cancioneiro Geral e a poesia peninsular de Quatrocentos (contactos e sobrevivência), Coimbra, 1978.

Margarida Vieira Mendes, Cancioneiro Geral de Garcia de Resende, in Dicionário da Literatura Medieval Galega e Portuguesa, Lisboa, Caminho, 1993, s.v.

Jorge A.Osório, «Do cancioneiro 'ordenado e emendado' por Garcia de Resende", in Revista da Faculdade de Letras. Linguas e Literaturas, Universidade do Porto, II Série, vol. XXII, Porto, 2005. p.291-335.

\section{Resumo}

Nas últimas décadas, a ordenação dos poemas dentro dos cancioneiros antigos tornou-se uma questão minuciosamente debatida pelos investigadores. A presente contribuição enfoca os critérios de disposição aplicados no Cancioneiro Geral de Garcia de Resende (1516), no intento de corrigir a autoria de uma célebre cantiga tradicionalmente atribuída a João Gonçalves de Castelo Branco (II 396 "Senhora, partem tam tristes»).

\section{Abstract}

Parmi les questions les plus débattues, le problème de l'arrangement des pièces à l'intérieur des anciens chansonniers a récemment fait l'objet de plusieurs études. Dans la présente contribution, on examine d'abord les critères suivis par Garcia de Resende quand il ordonna les poèmes du Cancioneiro Geral (1516), pour avancer ensuite une nouvelle hypothèse sur l'auteur d'une célèbre cantiga traditionellement attribuée à João Gonçalves de Castelo Branco (II 396 "Senhora, partem tam tristes »). 